\title{
ERRATA
}

Bungo Wada: Analysis of Mitosis. Cytologia Vol. 30

Suppl. Number (pp. 1-158) issued August 25, 1966

\begin{tabular}{r|c|c|c}
\hline \hline page & line & for & red \\
\hline $\mathrm{xi}$ & 28 & 56 & 57 \\
11 & in Figs. 1 a-h & $(19: 43)$ & $(12: 43)$ \\
58 & 1 & successful for & successful; for \\
67 & 25 & Haomantheus & Haemanthus \\
83 & 2 & comparing of the & comparing the \\
129 & 4 & (Fig. 35b) & (Fig. 35̄b). \\
144 & 12 & General Biology & General Cytology \\
150 & 11 & Aspergillus & Aspergillus \\
\hline
\end{tabular}

ANALYSIS OF MITOSIS : $x i i+158$ p. with 42 illus. and 3 tables. $\$ 6.00$

\section{Agents Agenturen Agents}

Tokyo: Maruzen Co., Ltd., Tôri 2-tyôme, Nihonbashi, Tyuôku, Tokyo

Tokyo: Nankôdô Co., Ltd., Harukityô 3-tyôme, Bunkyôku, Tokyo

Tokyo: Japan Publications Trading Co., Inc., Central P.O. Box 722, Tokyo

U.S.A.: Japan Publications Trading Co., (U.S.A.) Inc., 1255 Howard Street, San Francisco, California 94103 , U.S.A. 